\title{
A AMAZÔNIA NO SÉCULO 21: NOVAS FORMAS DE DESENVOLVIMENTO
}

\author{
Violeta Refkalefsky Loureiro
}

THE AMAZON IN THE 21TH CENTURY: NEW FORMS OF DEVELOPMENT

\section{RESUMO}

ESTE TRABALHO TEM COMO EIXO A SEGUINTE QUESTÃO: É VIÁVEL PENSAR EM OUTRA FORMA DE DESENVOLVIMENTO PARA A AMAZÔNIA BRASILEIRA - ALTERNATIVO ${ }^{1}$ EM RELACCÃO À VIA HEGEMÔNICA - SOB A QUAL OS HABITANTES E A NATUREZA DA REGIÃO NÃO SEJAM TÃO EXPLORADOS, A NATUREZA SEJA MELHOR CONSERVADA E OS CONFLITOS SOCIAIS, REDUZIDOS? COMO RESPOSTA, ESTE ARTIGO PROCURA ANALISAR A VIABILIDADE DE SE CONSTRUIR UMA VIDA MAIS JUSTA E DIGNA PARA TODOS, A PARTIR DE PARAMMETROS DE DESENVOLVIMENTO DIFERENTES, E POR ISSO ALTERNATIVOS EM RELAÇÃO AOS PARÂMETROS DEFINIDOS E IMPOSTOS PELO MODELO HEGEMÔNICO EM VIGOR NO MUNDO OCIDENTAL, QUE SE TEM MOSTRADO INDIFERENTE AOS INCONTÁVEIS DESACERTOS E MALES QUE DESENCADEIA NOS PAÍSES E REGIŌES PERIFÉRICAS. NÃO SE TRATA, AQUI, DE NEGAR A EXISTÊNCIA DE UMA GLOBALIZAÇÃO EM CURSO NO MUNDO E SEUS IMPACTOS, ESPECIALMENTE SOBRE AS REGIÕES PERIFÉRICAS; MAS DE ACREDITAR QUE APESAR DELA, E PARALELAMENTE A ELA, É POSSÍVEL DESENVOLVER MUDANCAS POSITIVAS E MUITO SIGNIFICATIVAS EM FAVOR DA REGIÃO E DE SEUS POVOS, DESDE QUE HAJA UMA MOBILIZAÇÃO DAS MUITAS FORÇAS INTERNAS E RECURSOS DE QUE A AMAZÔNIA DISPÕE.

PALAVRAS-CHAVE

AmAZÔNIA; FRONTEIRA; COMMODITIES.

\begin{abstract}
THIS PAPER FOCUSES ON THE FOLLOWING QUESTION: IS IT VIABLE TO THINK OF ANOTHER FORM OF AN ALTERNATIVE DEVELOPMENT FOR THE BRAZILIAN AMAZON - IN RELATION TO THE HEGEMONIC WAY - UNDER WHICH THE REGION INHABITANTS AND NATURE ARE NOT EXCESSIVELY EXPLOITED, NATURE BETTER CONSERVED AND SOCIAL CONFLICTS REDUCED? AS AN ANSWER, THE STUDY SEEKS TO ANALYZE THE VIABILITY OF CONSTRUCTING A FAIRER AND MORE DIGNIFIED LIFE FOR ALL, BASED ON PARAMETERS OF DIFFERENT DEVELOPMENTS, AND THEREFORE ALTERNATIVES IN RELATION TO THE PARAMETERS DEFINED AND IMPOSED BY THE HEGEMONIC MODEL CURRENTLY PRACTICED BY THE WESTERN WORLD, WHICH HAS DEMONSTRATED TO BE INDIFFERENT TO THE INNUMEROUS MISTAKES AND EVILS THAT SPREAD ALONG COUNTRIES AND PERIPHERAL REGIONS. THIS IS NOT ABOUT DENYING THE EXISTENCE OF A GLOBALIZATION PROCESS UNDERWAY AND ITS IMPACTS, ESPECIALLY THOSE ON THE PERIPHERAL REGIONS; BUT TO BELIEVE THAT DESPITE IT, IT IS POSSIBLE TO CONCURRENTLY DEVELOP POSITIVE AND VERY SIGNIFICANT CHANGES IN FAVOR OF THE REGION AND ITS PEOPLE, AS LONG AS THERE IS A MOBILIZATION OF THE MANY INTERNAL FORCES AND THE AMAZON AVAILABLE RESOURCES.

\section{KEYWORDS}

AMAZON; FRONTIER; COMMODITIES.
\end{abstract}

\section{INTRODUÇÃO}

A ideia de progresso, herdada do Iluminismo e da Modernidade histórica, encontrou na economia do capitalismo industrial dos países ocidentais hegemônicos sua mais perfeita e acabada expressão. O progresso material das sociedades ocidentais avançadas (em especial a norte-americana) converteu-se naquilo que desde os anos 1950 
passou a ser concebido como o modelo exemplar de desenvolvimento a que todas as sociedades ocidentais passaram a aspirar e os governos a perseguir. A identificação de progresso com desenvolvimento material se reflete e impregna todos os ângulos da vida social moderna. A nova forma de produzir exige total liberdade de mercado, processos produtivos globalizados, "flexibilidade de trabalho" e outros meios que tornaram a economia dos países instável e o trabalho das pessoas raro e volátil. Padrões de consumo crescentes de bens cada vez mais sofisticados converteram-se em aspirações irrenunciáveis e em valores equivalentes de cidadania e de justiça social.

Mas, além de o progresso ter-se convertido em expressão e em conceito equivalente de desenvolvimento material e de consumo individual crescentes, essa forma de desenvolvimento que procura imitar o dos países hegemônicos se apresenta para governantes, elites e amplos segmentos das sociedades ocidentais como a única via possível de alcançar o bem-estar social, o que, por sua vez, só a sociedade de consumo pode propiciar. A situação, portanto, é de uma circularidade tal que, para muitos, não há saída possível.

Mas, se esse padrão de desenvolvimento e consumo tornou-se a aspiração idealizada dos países periféricos, paradoxalmente, ele foi se tornando não apenas pouco recomendável como também irreprodutível no mundo atual. A impossibilidade dos países periféricos de reproduzirem a façanha dos países hegemônicos se deve a várias razões: a acumulação dos países centrais processou-se com base no antigo sistema colonial, na escravidão, nas guerras de conquista e na exploração dos países periféricos e esse processo histórico não pode ser refeito pelos países periféricos nos dias atuais; em segundo lugar, porque o modelo de desenvolvimento adotado tem gerado mais exclusão que igualdade social, e isso vem se tornando intolerável por parte dos menos favorecidos e dos excluídos sociais; em terceiro lugar, porque os recursos naturais do planeta tornaram-se insuficientes para garantir aos países periféricos o mesmo nível de consumo de que gozam os países centrais; em quarto lugar, porém não menos importante, porque o progresso material e a elevação dos padrões de consumo processaram-se em descompasso com o desenvolvimento moral, intelectual e humano das sociedades ocidentais, o que produziu um profundo e visível hiato entre os primeiros e os últimos. Esse descompasso vem gerando incontáveis consequências perversas e danosas para um número significativo de pessoas.

Tornou-se impositivo e urgente, portanto, buscar uma nova concepção de desenvolvimento, alternativo (no dizer de Boaventura de Souza Santos), em relação à via hegemônica e aplicável, pelo menos, aos países e regiões periféricas como a amazônica.

Após numerosos estudos realizados nas últimas décadas tutelados pela via hegemônica fica claro que as diversas experiências de desenvolvimento propostas para a Amazônia faliram em sua missão de desenvolver a região; são excludentes, 
comprometem ou destroem a rica multiculturalidade da Amazônia, levam à homogeneização cada vez maior das sociedades, dissolvendo num todo comum as particularidades e especificidades dos grupos sociais; são concentradores de renda, geram poucos empregos, espalham miséria em torno dos grandes empreendimentos onde se implantam e provocam enormes danos ambientais. É preciso, portanto, apostar em novas formas de organização da produção. E elas começaram a despontar desde o final dos anos 1980 por iniciativa de pequenos grupos de pessoas, organizados sob a forma de cooperativas, associações, ONGs, etc., ou por universidades - e já apresentaram resultados exitosos num número expressivo de casos.

Além das já existentes, é preciso também inventar e desenvolver outras iniciativas alternativas. São alternativas porque são norteadas por paradigmas mais solidários e distributivos e porque têm suas bases fincadas em formas próprias e mesmo inovadoras de organização da produção. São, além disso, socialmente mais integradoras que as convencionais e mais harmonizadas com a natureza.

As experiências negativas do passado recente na Amazônia evidenciam que é preciso estimular e apoiar outras formas de produção, que tragam em sua essência uma postura de reatamento das relações sociais, especialmente com as populações tradicionais e com as inúmeras etnias que povoam a região. Se ambas tiverem chance de expressão, podem sair da invisibilidade em que se encontram e revelar o mundo amazônico como um conjunto multicultural de diferentes grupos sociais, mais vivos e mais ricos culturalmente, ao conservarem suas individualidades e especificidades. Somente um outro modelo alternativo ao hegemônico, embora paralelo e contemporâneo a ele, pode evitar que as populações tradicionais e seus saberes desapareçam, que a sociedade e a natureza da Amazônia permaneçam sob a tutela de uma pseudorracionalidade científica e tecnológica que, por ser absolutizante e intolerante com as demais formas de organização da produção, tornou-se dominante, excludente e com a pretensão de ser única; e de uma ideologia obsessiva e equivocada que busca incessantemente o progresso e a modernização baseada nos modelos europeu e americano.

As formas de organização da produção convencionais prevalecentes, nas quais o governo brasileiro tem apostado como vias para o desenvolvimento da região, foram estabelecidas sob os princípios que regem os mercados mundiais, nos quais a Amazônia se insere de forma subordinada e em permanente desvantagem, apesar de sua biodiversidade ímpar. Depois de experiências fracassadas num passado mais distante, o atual modelo amazônico de desenvolvimento está ancorado em empreendimentos que produzem bens semielaborados (como ferro, alumínio, óleos de dendê e palma) e matérias-primas (como gado e soja), destinados à exportação. Apesar de gerar poucos empregos, já que as cadeias produtivas não se completam para produzir bens finais; de desalojar populações naturais e tradicionais; de consumir enormes quantidades de energia (inclusive com produção de carvão oriundo da queima da floresta nativa); de exaurir a natureza e colocá-la em permanente perigo, esse modelo de 
produção, baseado nas duas classes de produtos referidas - semielaborados e matérias-primas -, tem sido apoiado por políticas públicas continuadas, que reproduzem com poucas alterações o secular modelo agroexportador. Pelos males que carrega consigo, trata-se de desenvolvimento degenerativo, posto que quanto mais avança e se aprofunda, maiores danos provoca.

Outro ponto que deve ser esclarecido é o que se refere à finalidade do desenvolvimento. Embora os ganhos materiais estejam implícitos nos vários conceitos de desenvolvimento, este não pode se reduzir a resultados econômicos que, quando traduzidos em números, são tomados como ícones e expressões únicas do progresso e da modernização, menosprezando os danos causados às pessoas e à natureza. ${ }^{2}$

Este texto destaca quatro pontos que julgo importantes para a compreensão da Amazônia hoje: (1) alguns dos fundamentos epistemológicos pouco visíveis nos quais o modelo de desenvolvimento vigente na Amazônia se ancora; (2) a transformação da Amazônia numa nova fronteira - uma fronteira de commodities, aberta para o mundo; (3) as contradições do Estado brasileiro face à situação atual da Amazônia que, ultrapassando a condição de questão regional, converte-se cada vez mais rapidamente numa questão nacional e mesmo internacional; e (4) as novas possibilidades alternativas de desenvolvimento da Amazônia.

\section{FUNDAMENTOS EPISTEMOLÓGICOS POUCO VISÍVEIS DO MODELO VIGENTE}

Vários são os preconceitos e equívocos que nortearam no passado recente e continuam norteando o processo de desenvolvimento na região. Destaco aqui aqueles que aparecem com maior frequência nos meios oficiais, políticos e de comunicação de massa, dada a evidência que tiveram (e ainda têm) nas políticas públicas federais e estaduais para a Amazônia. ${ }^{3}$

O primeiro deles refere-se ao erro de conceber a Amazônia como um macrossistema homogêneo de floresta e rios, assentado sobre uma extensa planície. Esse equívoco é responsável pelo fato de que atividades econômicas tão diversas como a pecuária, a exploração madeireira, a mineração, a garimpagem e outras, que apresentam diferentes impactos sobre a natureza, tenham sido e continuem a ser desenvolvidas, indiferentemente, sobre áreas de florestas densas, nascentes e margens de rios, regiões de manguezais, nas planícies, em encostas de montes, em solos frágeis ou nos raros solos ricos e bem estruturados da região.

A ideia de que a floresta em pé e sua biodiversidade valem mais do que os produtos semielaborados, ${ }^{4}$ que hoje são extraídos dela ainda, é partilhada por segmentos sociais muito restritos da sociedade regional. Ao contrário, a natureza em geral, e em especial a floresta são tomadas como expressão de primitivismo e de atraso, por contrastar com o plantio de culturas ditas "racionais" - porque organizadas sob o formato de monoculturas, homogêneas e modernas, que caracterizam a agricultura dos países 
centrais, e são imitadas pelos países periféricos, num processo de "mimetismo colonial", no dizer de Homi Bhabha. ${ }^{5}$

Além desses, há os equívocos de fundo cultural que vêm de longa data, como a ideia de que a natureza amazônica é superabundante, resistente, inesgotável e autorregenerável; por isso, empresários e aventureiros de toda ordem, ignorando que a Amazônia é o maior banco genético do mundo, separam biodiversidade (como um tema exclusivo e restrito aos estudos científicos) da floresta que exploram exaustivamente; entendem que índios e os caboclos vivem em terras excessivamente vastas e as ocupam em atividades pouco rentáveis para o Estado e de forma incompatível com a economia e a sociedade contemporâneas; suas atividades produtivas - o extrativismo vegetal em especial - são consideradas primitivas, arcaicas, antieconômicas e não merecedoras de apoio e aperfeiçoamento; por isso, as políticas públicas não estimulam o enriquecimento da floresta para um aproveitamento mais vantajoso, apesar de milhares de pessoas na região viverem de atividades extrativas.

Entendo, como Boaventura de Sousa Santos, que a forma atual e predominante como se estabeleceu nos últimos séculos o contrato social nas sociedades ocidentais, imposto pelo sistema democrático-liberal, visando apenas a reprodução do capital, gerou uma grave crise no sistema-mundo. ${ }^{6}$ Essa crise reside no fato de que predominam cada vez mais fortemente os processos de exclusão social sobre os processos de inclusão social. ${ }^{7}$ As populações tradicionais são povos atrasados, primitivos, portadores de uma cultura inferior, que obstaculizam o desenvolvimento e só têm a ganhar integrando-se à sociedade urbana e "civilizada”, desocupando suas terras para atividades ditas modernas. ${ }^{8}$ Sob a óptica integracionista, as terras indígenas ${ }^{9}$ seriam situações provisórias e tendentes a desaparecer à medida que os índios forem assimilados - pelas mais diversas vias - à sociedade nacional, desaparecendo dentro dela, diluindo assim, "o atraso" e o "primitivismo" que os tornam diferentes e os afastam dos padrões civilizados da sociedade moderna.

A multiculturalidade (em especial representada pelos grupos indígenas) é entendida como um elemento negador do desenvolvimento, da modernidade e de uma pretensa e almejada unidade nacional, estabelecida com base no imaginário de uma nação única e de um povo único - o povo brasileiro.

\section{Amazônia como fronteira de commodities, ABERTA PARA O MUNDo}

A partir de meados dos anos 1980 a Amazônia como fronteira econômica foi se desviando cada vez mais da produção familiar e voltando-se para a produção de commodities e para a exploração de minérios e de madeiras (esta especialmente de forma ilegal). ${ }^{10}$ Daí porque, hoje, entendo que a região converteu-se numa fronteira de commodities. Na verdade, desde meados dos anos 1990 ela já estava claramente definida como tal, embora a questão da Amazônia sob esse ângulo mais específico não 
tenha sido levantada. Hoje, a Amazônia como fronteira apresenta uma conotação bem particularizada: articula-se e é impulsionada diretamente, e mais intensamente, pelo mercado internacional e, muito menos, pela conjuntura e pelo mercado nacionais. E a exploração dos recursos naturais igualmente oscila segundo a demanda desse mercado de commodities (madeira, minérios, gado, ${ }^{11}$ dendê, palma e, mais recentemente, a soja e outros produtos). Trata-se, portanto, de uma nova fronteira, onde o campesinato não tem mais o papel de protagonista.

Assim, a expansão da fronteira apresenta uma grande independência em relação às oscilações do mercado interno, já que a grande motivação para sua expansão é, agora, o mercado internacional. Ela passa a oscilar, na medida em que a demanda e os preços desses produtos variam no mercado internacional. São eles que vêm influenciando a abertura acelerada de novos espaços de produção, que alcançam e rasgam o coração da floresta, abrindo-a simultaneamente em várias direções e dificultando as ações de fiscalização e de controle por parte do Estado.

Esses produtos são exportados pelos estados amazônicos e vendidos in natura ou como semielaborados, como têm sido há séculos. Embora as formas de extraí-los e explorá-los lance mão de tecnologias avançadas (grandes plantas industriais, equipamentos pesados e outros), o modelo se repete como secularmente vem sendo: concentrando renda, aproveitando-se da superexploração do trabalho humano e com uma enorme exaustão da natureza. ${ }^{12}$

\section{DAs CONTRAdiçÕes do Estado BRAsileiro E DOS GOVERnOS}

Através das commodities produzidas na região o país se beneficia, quando consegue equilibrar a balança comercial, valendo-se dos elevados saldos, que resultam da contribuição superavitária que os estados produtores dessas commodities possibilitam. Mas, o que os governos consideram ganhos, exibindo resultados numéricos, trazem embutidos várias contradições.

Em primeiro lugar, trata-se de uma estranha contabilidade pública, na qual os dados positivos apresentados pelos governos não registram e nem descontam nenhuma das inúmeras perdas sociais, como, por exemplo, a formação de grandes massas de populações urbanas periféricas, constituída de habitantes naturais e migrantes, que ficam sem condições de permanecer em suas terras, sendo expulsos delas para cederem lugar aos grandes empreendimentos que, hipoteticamente, promoverão o desenvolvimento da região.

Em segundo lugar, porque omite nessa contabilidade que os indicadores apresentam como positivos as perdas econômicas resultantes da concessão de subsídios; os custos da infraestrutura construída com recursos públicos, específica ou prioritariamente voltados para esses projetos; as vantagens e facilidades financeiras concedidas pelo poder público, que sacrifica o restante da sociedade ao canalizar esses recursos 
para fins privados. Em terceiro lugar, porque não desconta como perda o esgotamento dos recursos naturais ou a exaustão dos frágeis solos amazônicos; e considera recurso renovável uma floresta que jamais se renovará com a mesma biodiversidade de antes, posto que a natureza amazônica levou muitos séculos, talvez milênios, para se formar com a biodiversidade que hoje apresenta (que também não é contabilizada como perda).

Essas contradições conduzem a algumas inferências. Em primeiro lugar, a fronteira mudou sua natureza, transformando-se numa fronteira de commodities, aberta para o mundo e influenciada diretamente pelo movimento das commodities internacionais e menos pelas políticas internas do país. E o processo ocorreu e ocorre com o estímulo e apoio do Estado, independentemente dos danos sociais e ambientais que vêm provocando desde então.

Em segundo lugar, a fronteira transformou-se, alargou-se em várias direções e assombra as populações amazônicas, ao se espraiar em vários sentidos, absorvendo terras e expulsando populações, desde Roraima, no extremo norte, estendendo-se pelos limites sul e sudoeste de Rondônia e Acre, adentrando pelo norte de Mato Grosso, envolvendo grande parte de Tocantins, o sul e o sudeste do Pará; e agora, penetrando o coração da Amazônia, quando sobe em direção ao centro do Pará, onde duas grandes infraestruturas estão sendo construídas: a rodovia BR-163 (a SantarémCuiabá) e a hidrelétrica de Belo-Monte, no rio Xingu. Ambas causarão enormes danos sociais e ambientais porque ameaçam a multiculturalidade dos povos que habitam as áreas afetadas - a rodovia atingindo 31 etnias indígenas. ${ }^{13}$ Quanto à hidrelétrica, o EIA/RIMA, ${ }^{14}$ já foi reformulado várias vezes por exigência do Judiciário, na tentativa de minorar os danos às populações a serem remanejadas; além disso, inúmeros estudos demonstram outras soluções energéticas (como a redução das perdas de energia nas grandes cidades em virtude do envelhecimento dos sistemas de distribuição).

Ambos os empreendimentos já vem intensificando o processo de grilagem de terras e os conflitos sociais, além de provocarem graves danos ambientais: a rodovia, por exemplo, já provocou uma aceleração e intensificação do desmatamento numa área central da Amazônia.

Em terceiro lugar, a abertura e a expansão da fronteira em vários sentidos, simultaneamente, retirou do Estado o já restrito controle que o mesmo tinha sobre a Amazônia.

Em quarto lugar, não houve uma modernização no sentido de uma melhoria das condições de vida das populações. Isto se deu por um conjunto de razões encadeadas: a exportação dos produtos gerados pelas grandes indústrias é feita com os produtos in natura ou sob a forma de semielaborados (ferro e alumínio em lingotes, p.ex.), não há uma diversificação de produtos e apenas algumas dezenas de grandes empresas controlam toda a produção e a comercialização dos mesmos, constituindo-se sob a 
forma de "modernos enclaves", ditos modernos porque se utilizam de máquinas e equipamentos eficientes e sofisticados que elevam a produção e a produtividade, mas não beneficiaram os ganhos do trabalho. Como essas empresas não processam internamente os produtos nem fazem sua finalização na região, como consequência, não internalizam benefícios, não distribuem renda e nem desencadeiam o surgimento de médios e pequenos negócios decorrentes dos grandes empreedimentos, pelas razões já referidas.

A geração de emprego tem sido irrisória e os salários pagos são baixos. Fora das grandes empresas siderúrgicas e outras, o dito processo de modernização não eliminou o trabalho árduo na exploração da madeira, na formação de pastos, na criação do gado, na abertura de estradas, na construção de usinas e em outras atividades; ao contrário disso, o desmatamento para o plantio ou a formação de pastos e a produção de carvão vegetal da mata nativa para as indústrias siderúrgicas reviveram formas perversas e arcaicas de trabalho, como a peonagem e o trabalho escravo. ${ }^{15}$

Certamente, não se pode falar em modernização quando não ocorre uma correspondente participação da sociedade nos benefícios materiais e imateriais gerados pelo crescimento econômico. Quando, ao contrário, o modelo restaura formas perversas e arcaicas de exploração do trabalho humano ${ }^{16}$ quando o processo aumenta as desigualdades locais e entre regiões; quando empobrece a região naquilo que ele tem de maior valor - sua biodiversidade. Assim sendo, o conceito de modernização foi-se esvaziando completamente, à medida que se referia a fenômenos sociais os mais diversos, de tal modo que, hoje, mesmo o fato de roubar famílias e comunidades inteiras de seus meios originais de subsistência é chamado de "modernização". 17

Os danos ambientais estão por ser calculados, quando se puder incluir num novo tipo de contabilidade social e econômica a perda da biodiversidade e o esgotamento dos recursos naturais. Apenas quanto à floresta, mais de 500 mil quilômetros quadrados de áreas foram desflorestadas. E são os estados mais desmatados aqueles que apresentam os mais baixos Índices de Desenvolvimento Humano (IDH). ${ }^{18}$ Sob esse aspecto, o modelo vigente permanece com um forte traço de irracionalidade, quando provoca danos sociais e ambientais consideráveis, muitos dos quais irreversíveis. Sob esse último aspecto, as atividades consideradas tradicionais dos caboclos e dos índios da região, pelas suas características no que concerne à responsabilidade ambiental conservação da biodiversidade e à sustentabilidade dos recursos naturais da região embora contestadas pelas políticas públicas, acusadas de serem pouco produtivas sob a óptica do capital, e rejeitadas por não resultarem de investigação científica, parecem estar muito mais próximas de um novo conceito de modernidade, já que incluem a preocupação com a sustentabilidade da natureza, elemento que só nos últimos anos vem entrando na pauta de questões referentes aos destinos da Amazônia.

Portanto, as transformações recentes, pelo menos aquelas que ocorreram a partir dos anos 1970, constituem um processo que venho designando pelo termo modernização 
à avessas, ${ }^{19}$ porque trata-se do velho modelo travestido no novo; do tradicional, apresentado sob a forma de moderno, de novo.

E, finalmente, constata-se que o Estado brasileiro se vê enredado na complexidade dessa situação, e nela se comporta de forma oscilante e dúbia porque, ao mesmo tempo em que aspira a lucros cada vez maiores, decorrentes da produção de commodities, fere direitos humanos fundamentais das populações locais e tradicionais, e ainda quando coloca as últimas em risco de desaparecer física ou culturalmente, ao menosprezar a rica multiculturalidade dos povos que povoam a Amazônia. ${ }^{20}$ Além disso, o Estado tem que enfrentar os movimentos sociais em defesa dos direitos humanos e sociais e das questões ambientais.

Sob o argumento do crescimento econômico, do progresso e da modernização do país, o governo federal não tem poupado esforços na execução de projetos de impacto, como a rodovia BR-163, que, se substituída por uma estrada de ferro, acarretaria impactos sociais e ambientais muito menores, embora essa alternativa sequer tenha sido cogitada; e a hidrelétrica de Belo-Monte, no rio Xingu, questionada judicialmente durante mais de vinte anos e hoje em construção; ambos projetos afetam o modo de vida e a sobrevivência cultural de grupos indígenas e populações locais. Ora, nada justifica violações atentatórias aos direitos das minorias, sabidamente hipossuficientes frente aos grupos econômicos e ao Estado. Um Estado moderno é tanto mais democrático quanto mais serve ao real interesse público, protege as minorias da violência social, resguarda a natureza contra a predação desmedida (como a que ocorre na região) e concilia o real desenvolvimento com respeito aos direitos humanos e à natureza. ${ }^{21}$

Não se pode falar em desenvolvimento ou modernização enquanto os órgãos oficiais apresentam, através de uma estranha contabilidade, apenas os resultados numéricos positivos que resultam de um modelo econômico socialmente perverso. Mas os governos o fazem, mobilizando o sentimento nacional em nome do progresso e da melhoria futura das condições de vida das populações do país, enquanto o presente vem, teimosamente, desmentindo essa promessa, em especial para as populações da região.

\section{Novas alternativas PARA O DeSENVOlvimento}

Como o que se propõe é uma nova forma de desenvolvimento que privilegie o social, o local, o regional e os valores éticos, em especial a solidariedade e a integração e, como tais características em tudo se opõem àquelas preconizadas pelo modelo de desenvolvimento proposto pelo mercado mundial globalizado, o termo proposto por Boaventura de Sousa Santos, desenvolvimento alternativo, ${ }^{22}$ parece ser um dos mais adequados para designar o novo modelo. No mesmo sentido, posto que com o mesmo espírito, encontra-se sugerido por Francisco Buey ${ }^{23}$ e vários outros autores que têm refletido sobre uma nova modalidade de desenvolvimento. 
Em trabalho recente ${ }^{24}$ proponho o termo um outro desenvolvimento. O termo, a meu ver, pressupõe e remete, imediatamente, a uma oposição ao desenvolvimento em sua forma hegemônica, centrada na individualização e na maximização do consumo, propondo-se como uma alternativa a ele. Esse outro desenvolvimento que ora apenas se insinua na região, convive paralelamente com o modelo hegemônico. Mas poderá um dia, se expandido, neutralizar os efeitos danosos do primeiro ou estimular o direcionamento daquele, ao mesmo tempo em que produz consequências benéficas para um maior número de pessoas. Em linhas gerais, alguns dos princípios norteadores desse novo e alternativo modelo seriam os que seguem:

a) Respeitar as populações locais, especialmente as populações tradicionais e os grupos étnicos, em seus saberes e em suas identidades culturais, incorporando o conhecimento dos mesmos sobre a região, especialmente aquele concernente à natureza e às relações com ela, bem como a incorporação dessas populações como elementos importantes nas transformações em curso.

b) Desenvolver formas ou vias de desenvolvimento que priorizem a inclusão social das comunidades e a sustentabilidade da natureza, de modo a preservá-la para as gerações futuras e na qual ou nas quais o fator econômico e a acumulação do capital por grupos restritos não seja o principal e muito menos o único valor a ser considerado para a tomada de decisão.

c) Estabelecer um diálogo mais equilibrado, verdadeiro e solidário entre o Estado e as populações locais e tradicionais, especialmente quando se tratar de empreendimentos estatais que as afetam em suas vidas, culturas e identidades.

d) Entender que as áreas já devastadas na região correspondem à superfície de vários países da Europa somados e, portanto, não há necessidade de desmatar nenhum hectare mais, sob a justificativa de que é preciso desenvolver a região ou "porque ela não pode ser mantida intocável", conforme o discurso dos que não tem interesse em poupá-la e sim em enriquecer à custa dela. Nenhuma região do mundo tem sido no último século mais violentamente tocada e modificada, muitas vezes de forma irremediável, em sua natureza. Os governos devem pensar em mecanismos para sustar novos desmatamentos, tais como: (1) controlar rigorosamente áreas bem definidas que apresentam elevado risco social e natural; (2) cogitar a concessão de uma bolsa-floresta para famílias que habitam nas matas e se responsabilizem pelo não desmatamento, e sim pelo desenvolvimento de ações de valor comercial e enriquecedoras da floresta ; ${ }^{25}$ e (3) negociação com os países mais preocupados com a questão ambiental (inicialmente) para levantar recursos com vistas à criação de fundos específicos, capazes de compensar a 
manutenção da floresta em pé e de monitorar/fiscalizar o abate indiscriminado de árvores. ${ }^{26}$

e) Voltar-se para a natureza em vários sentidos: (1) aproveitamento das áreas já devastadas rentes à floresta para atividades agrícolas, combinando várias culturas para alimentação do agricultor e, simultaneamente, desenvolver culturas comerciais como: cacau, banana, guaraná, castanheiras precoces, palmeiras de açaí, pupunha, mandioca e outras espécies, valendo-se do benefício da umidade que ainda emana das áreas florestadas que ficam próximas às áreas desmatadas, mas situadas nas bordas da mata; ${ }^{27}$ (2) enriquecimento da floresta nativa com espécies de elevado valor comercial; (3) aproveitamento da floresta nativa, para extrair dela o que o seu rico potencial pode oferecer, mantendo o máximo de floresta em pé; e (4) reflorestamento de áreas devastadas, com o objetivo de recuperar os solos e melhorar as condições atmosféricas da região e do planeta.

f) Promover a mudança da base produtiva regional - hoje apoiada na exportação de produtos semielaborados num extremo, e em atividades tradicionais de baixa produtividade noutro, reduzindo o abismo existente entre ambas -, completar as cadeias produtivas, até chegar a finalizar produtos na própria região, contribuindo para que a Amazônia seja, não apenas um lugar de abundância natural, mas também um lugar de justiça e de bem-estar social.

g) Intensificar, através da pesquisa, o estudo do aproveitamento de espécies florestais e animais da Amazônia, reforçando as equipes de pesquisa e os laboratórios de universidades e institutos da região. Criar e disseminar, através de políticas tecnicamente bem orientadas e financeiramente viáveis, viveiros de espécies florestais, bancos de células de espécies em risco de extinção e o criatório de espécies animais naturais da região - sempre respeitando a biodiversidade, ${ }^{28}$ já que, como se tem constatado historicamente, os ecossistemas amazônicos não toleram a homogeneidade que o mercado teima em exigir deles.

Após apontar alguns dos princípios norteadores de um outro desenvolvimento, o que faço a seguir é explicitar, sem a pretensão de esgotar, algumas possibilidades concretas de desenvolvimento alternativo, a partir de experiências já desenvolvidas na região, sem esquecer que muitas outras podem ser concebidas e desenvolvidas a partir dos mesmos princípios. Reporto-me aqui às práticas consideradas viáveis e ao alcance das populações e das agências governamentais locais, que, portanto, independem de articulações que dependem do sistema-mundo.

Algumas já se revelaram promissoras, outras são ainda incipientes, outras precisam ser identificadas ou melhor conhecidas e, finalmente, outras ainda podem, mas 
não foram encetadas. São experiências e possibilidades que se situam num contexto social próprio e numa natureza singular - a amazônica. Disso resulta que a sobrevivência de algumas dessas experiências pode ser duvidosa face ao abandono a que a maioria se encontra relegada pelo Estado (em suas várias esferas político-administrativas, federal, estadual e municipal), que considera essas iniciativas inferiores aos grandes empreendimentos.

\section{DA RESPONSABILIDAdE DO ESTAdo EM SUAS VÁRIAS ESFERAS}

\section{I CoRreÇÃo de PRÁticAs, DirecionAmENTO OU VÍ́CIOS} NA ROTINA DE ÓRGÃos PÚBLICOS

São incontáveis as práticas administrativas nos mais diversos campos que, simplesmente, por serem mal conduzidas ou pelo caráter elitista e privilegiador do Estado brasileiro, se opõem ao desenvolvimento sustentável, são estimuladores de injustiça social e de conflitos. Além dos grandes programas nacionais, a prática administrativa de um significativo número de instituições públicas (federais ou não), sediadas na região, em geral, ignora as práticas e interesses das populações locais ou agride a sustentabilidade da natureza amazônica. Apresentaremos alguns exemplos danosos dessas situações, na órbita do Estado.

\subsection{ESTímulo À MONOCULTURA ATRAVÉS DAS LINHAS DE FINANCIAMENTO}

O estímulo à monocultura, por meio de de linhas de financiamento conseguidos de agências financiamento e bancos de desenvolvimento, é uma orientação que afronta os ecossistemas amazônicos que, como a história antiga e recente já demonstrou inúmeras vezes, são avessos à monocultura. São exemplos desses fracasos as experiências com a borracha, o cacau, a pimenta-do-reino, o cupuaçu e outras culturas, todas elas atacadas por pragas devastadoras, devido ao clima superúmido da região e à quebra da biodiversidade dos ecossistemas que a monocultura impõe.

\subsection{Mudança no Comportamento tolerante do Estado QUANTO Às AÇõES ABUSIVAS E/OU ILEGAIS}

A simples proibição de compra de carvão vegetal de floresta nativa pela indústria siderúrgica na Amazônia e o plantio de florestas próprias (imposto por lei há mais de uma década, sem resultados visíveis), já reduziriam enormes áreas desmatadas a cada ano. Não se justifica apontar qualquer dificuldade de fiscalizar sob a alegação da vastidão da região; neste caso, bastaria fiscalizar a entrada das indústrias siderúrgicas que compram o carvão vegetal e a procedência do mesmo. Se não vêm de suas próprias áreas plantadas, qual seria a origem? Geralmente o carvão é produzido por pequenos produtores rurais, que vendem a mata no fundo do seu lote para ter acesso a algum 
dinheiro, de mata de terra pública ou de área de terceiros. Mais ainda: se o Estado cobrasse das siderúrgicas, com rigidez, a obrigação de produzir carvão a partir de áreas reflorestadas e próprias, tal como dispõe a legislação em vigor, os empregos gerados seriam muito mais numerosos do que os atuais subempregos que a simples queima da mata para a produção de carvão de floresta nativa gera.

\subsection{IMPUNIDADE NOS CASOS DE MORTES NO CAMPO,} TRABALHO ESCRAVO E GRILAGEM DE TERRAS

Embora haja muitos setores em que o Estado é tolerante em relação às diversas formas de transgressões e abusos praticados por grupos econômicos e empresas privadas na região, destaco aqui aquelas ligadas à prática de três delas, que considero as mais graves: a pistolagem, o trabalho escravo e a grilagem de terras. ${ }^{29}$

No que concerne à pistolagem, a impunidade na Amazônia chega a ser vergonhosa: de 1985 a 2008 foram assassinados 819 trabalhadores na defesa da terra, somente no Pará. Desse total, apenas 92 casos converteram-se em processos, apenas 22 chegaram a julgamento e houve apenas 6 condenações de mandantes, mas em 2008 nenhum deles estava preso (CPT-PA, 2009). ${ }^{30}$

Quanto ao trabalho escravo, a quase totalidade dos juízes julga a questão como simples quebra nas leis trabalhistas. Em vez de considerarem o trabalho escravo uma violação dos direitos humanos, boa parte dos juízes exige dos empresários apenas o pagamento das dívidas salariais atrasadas e a assinatura de contratos de trabalho, após o quê, toma a questão como regularizada; isso estimula um elevado nível de reincidências.

A grilagem de terras e o registro de terras ilegalmente compradas são práticas amplamente disseminadas e evidentes. Segundo dados apurados pela Comissão Permanente de Monitoramento, Estudo e Assessoramento das Questões Ligadas à Grilagem, designada pelo Tribunal de Justiça do Estado, com o apoio do Instituto de Terras do Pará (IETRPA), com poderes para tal, que lhe foram atribuídos pelo Provimento n. 13/2006 daquele TJE do Pará, no Pará, há municípios cujas áreas registradas em papéis, sob a forma de títulos de terra os mais diversos, correspondem a muitas vezes a área total do município. É o caso de Moju (15,9 vezes a área do município); São Félix do Xingu (3,4 vezes); Tucuruí (9,4 vezes) e de dezenas de outros. ${ }^{31}$ Face ao trabalho da referida comissão, milhares de títulos de terras griladas começaram a ser anulados. Resta consolidar a ação, com o confisco das terras - operação difícil devido à força que os ruralistas, ainda que sejam grileiros, têm nas assembleias legislativas dos estados e na Câmara Federal; e, finalmente, se confiscadas, falta registrá-las no cadastro de terras dos estados e da União. Há portanto, um longo e difícil caminho pela frente.

\subsection{NegOciaÇÃo do Estado COM GRANDES GRUPOS ECONÔMICOS SIDERÚRgICOS E AGROPECUÁRIOS PARA INTERNALIZAR BENEFÍCIOS NA REGIÃo \\ É tarefa de o Estado negociar formas de internalização de benefícios pelas indústrias}


siderúrgicas e outras empresas, como as agropecuárias, que têm sido aquinhoadas com financiamentos governamentais subsidiados nas últimas décadas, sem contrapartida por parte delas para a região. Isto pode ser feito de diversas maneiras: (1) pela aplicação de parte dos lucros na área social; ${ }^{32}$ (2) pela exigência de reflorestamento, o que criaria inúmeros empregos e daria cumprimento à legislação vigente; (3) pela implantação de novas indústrias de menor porte, as quais, complementando as cadeias produtivas existentes, poderiam beneficiar os produtos internamente e produzir vários outros localmente, e (4) substituindo a simples exportação dos minérios sob a forma de semielaborados ou in natura por produtos acabados.

\subsection{EXeCUÇÃo de Programas eSSENCiais PARA A REgião, QUE REQUEIRAM ESFORÇO NACIONAL}

As bancadas políticas regionais devem empenhar-se junto ao Governo Federal na participação conjunta com vistas ao aporte de recursos extraordinários para a execução de pelo menos alguns projetos. Elaboração do zoneamento econômico-ecológico dos estados da região. Este é um instrumento indispensável para que a exploração de atividades econômicas ocorra de forma compatível com as características e possibilidades de cada um dos variados ecossistemas amazônicos. O zoneamento precisa ser feito numa escala que permita operacionalizar as rotinas necessárias ao planejamento e à fiscalização, e deve ser acompanhado da legislação pertinente, que precisa ser compatibilizada segundo esfera político-administrativa (federal, estadual, municipal) e segundo setores (meio ambiente, territórios étnicos, etc.).

\subsection{COMPATIBILIZAÇÃO doS diversos CADASTROS DE TERRAS ATUALMENTE EXISTENTES}

Os espaços amazônicos encontram-se vinculados a cadastros que não se comunicam entre si, posto que estão vinculados a esferas administrativas distintas, têm destinações diferentes e são regidos por diferentes leis e procedimentos administrativos. O problema é que muitos desses espaços se superpõem, as legislações conflitam e as instituições adotam procedimentos administrativos e gerenciais diferentes ou antagônicos sobre os mesmos espaços. Daí porque essa compatibilização exige um esforço conjugado, e urgente, entre as várias esferas quanto aos cadastros, aos usos próprios a cada espaço ou território definido, e às legislações e normas pertinentes a cada qual. Grande parte desses usos e suas legislações são conflitantes entre si (mesmo quando as terras e seus correspondentes papéis se encontram sob a mesma esfera, como os do Incra, da Funai e do Ministério do Meio Ambiente). Assim sendo, somente a compatibilização dos cadastros federais e estaduais poderá equacionar ou, pelo menos, amenizar o caos fundiário, possibilitando o controle das fraudes e grilagens cometidas e por cometer no futuro, além de reduzir os conflitos de terra na região. 


\subsection{ORgAnização de CAdASTROS}

Um trabalho que decorre da organização de cadastros é a compatibilização e, em alguns casos, a eliminação da sobreposição de áreas protegidas (indígenas com florestas nacionais, p.ex., e inúmeros outros casos). A ocorrência de superposições de áreas protegidas costuma gerar conflitos porque são terras regidas por legislações distintas e, com frequência, com usos previstos em lei, os quais são incompatíveis entre si. Além disso, há espécies florestais e animais protegidas, não apenas fora dessas áreas mas também dentro elas, como a castanha-do-pará e o mogno, cujos usos estão regulados em legislação específica.

\subsection{Correção e reorientação do Fundo Constitucional Norte (FNO)}

O Fundo Constitucional Norte (FNO) foi criado após a Constituição de 1988 como o mais auspicioso fundo de desenvolvimento da região, na prática, porém, apresentou-se como um instrumento que poucas mudanças substanciais trouxe. As exigências pedidas ao financiado são tais que o mesmo deve ter em bens o equivalente a cerca de cem por cento ou mais em relação ao valor do empréstimo tomado. Assim, apenas empresários já capitalizados fazem jus às exigências, o que reproduz a concentração de renda e esvazia a força que potencialmente o fundo tem.

\section{AÇÕES PROATIVAs de PARTE DO ESTAdo, UNIVERSIDAdES E ÓRGÃOS DE PESQUISA}

\section{I Apoios InSTITUCIONAIS INDISPENSÁvEIS}

A criação de novas oportunidades sob a forma de pequenos empreendimentos ancorados nos saberes locais não dispensa a ajuda do Estado e das redes de apoio, seja com a finalidade de oferecer assessoria técnico-científica, seja financeira, até o estágio em que elas, apesar da fragilidade face à concorrência do mercado global, consigam sobreviver e se firmar, apresentando resultados concretos e visíveis. De modo geral, na Amazônia o Estado tem ignorado essas experiências ou minimizado a importância de alternativas coletivas de organização da produção. É necessário, entretanto, que o Estado ultrapasse a visão puramente assistencialista da questão e dê início a uma nova política de desenvolvimento que englobe possibilidades inovadoras. Destaco aqui a importância de assessorias relativas à garantia de qualidade, inclusive sanitária, dos produtos; durabilidade e forma de conservação, armazenamento e embalagem (processos que exigem o tratamento químico dos produtos); identificação dos tipos de beneficiamento mais favoráveis, de apresentação mais apropriada e outras formas de apoio, como a orientação na elaboração da contabilidade da microempresa (mesmo que simplificada); informações sobre o mercado e outros itens que, se não são complexos e onerosos, por sua vez não dispensam apoios institucionais básicos, pelo menos em sua fase inicial. 


\subsection{DeSENVOLVIMENTO DE PESQUiSAS INSTITUCIONAIS VOLTADAS PARA APROVEITAMENTO} DA BIODIVERSIDADE AMAZÔNICA E SOLUÇÕES DE PROBLEMAS REGIONAIS

O que se observa é que as experiências realizadas espontaneamente, por produtores individuais ou associações de pequenos produtores, ficam penalizadas pela falta de pesquisas específicas voltadas para o aproveitamento de determinados produtos derivados de espécies regionais, além dos apoios suprarreferidos. ${ }^{33}$ Acresce a isto o fato de que parte dos produtores possui um nível de ensino formal baixo, o que requer um assessoramento mais próximo e assíduo.

Nesse ponto, Estado e universidades podem apoiá-los enormemente, não apenas com pesquisas, mas com a implantação de incubadoras de empresas e outros serviços, montando uma linha eficiente de conexão ligando três elementos-chaves: universidades/pesquisa + Estado + pequena/média empresa. A Universidade Federal do Pará (UFPA) implantou incubadoras de empresas, testou e finalizou diversos produtos de excelente qualidade, no entanto, os resultados não foram exitosos na maior parte dos casos porque os inventos não chegaram ao mercado por falta de uma conexão mais efetiva entre a tríade básica do processo: universidades, Estado e empresas.

Vários produtos foram e continuam a ser gerados. Uma forte razão pela qual eles não chegam ao mercado é a inexistência de uma linha de crédito específica nos bancos e agências de desenvolvimento, voltada para esse fim, de forma a estimular investidores em empreendimentos inovadores que, por isso mesmo, apresentam maior risco. Outra razão é o desconhecimento do mercado onde o produto possa ter uma boa acolhida.

Essas razões apontam no sentido de que o Estado deveria articular-se melhor com as universidades, empresas, bancos de desenvolvimento, federações de indústria e de comércio, classes empresariais e outros segmentos, enfim, responder pelo caminho crítico que vai da criação do produto à sua produção artesanal ou industrial. A pesquisa aplicada, dentro ou fora de incubadoras de empresas, é um recurso indispensável para revelar possibilidades e oferecer maior segurança a esses pequenos investidores, mas ela não supre a totalidade de requisitos necessários. Essas experiências inovadoras são desenvolvidas por organizações que operam com sistemas de produção não tipicamente capitalistas (onde predomina o trabalho associativo, cooperativo, de grupos de comunidade ou outros do gênero). Assim sendo, é necessário implantar ações voltadas para a formação de gestores, com vistas a tornar esses pequenos empreendedores em grupos capazes de viabilizar a gestão dos empreendimentos, estejam eles a cargo de cooperativas, associações ou grupos menores de pessoas. Eles, contudo, não podem funcionar independentemente dos outros elementos - mercado, Estado e universidades. Cabe ao Estado assumir um papel mais ativo, coordenando as políticas e ações que requerem a participação dos outros elementos do sistema. 


\section{Alternativas ao modelo hegemônico através de Pequenos EMPREENDIMENTOS LOCAIS GERADORES DE EMPREGO E RENDA: ALGUNS EXEMPLOS 34}

É preciso considerar que, tanto no que concerne ao mercado quanto em relação à natureza, a questão amazônica é regional apenas no sentido de que é localizada espacialmente. No entanto, ela implica uma série de envolvimentos e condicionantes de caráter nacional e global.

Apesar das relações de produção e comercialização em todo o mundo estarem bastante inseridas no processo de globalização, o que inclui os próprios processos de produção em escala, com componentes sendo fabricados em países diferentes, e apresentem uma tendência ao agigantamento, há lugar no mundo globalizado para os pequenos empreendimentos. Isso acontece por várias razões, que dão espaço aos pequenos negócios.

a) Os grandes empreendimentos globalizados não se interessam por pequenos mercados nem por produções variadas e em quantidades reduzidas, mas apenas pela produção em grande escala.

b) Os pequenos empreendimentos aqui cogitados são de caráter local - embora alguns deles possam crescer e projetar-se além do espaço regional -, e envolvem as populações locais e seus saberes acerca da natureza em que vivem. Esses conhecimentos, mesmo que possam ser apoiados científica e tecnicamente, dispensam estudos complementares muito aprofundados e podem ser aplicados à criação de bens, produtos e serviços, conferindo renda, emprego e melhoria dos padrões de vida.

c) Os pequenos empreendimentos destinam-se preferencialmente aos mercados locais e direcionam-se a um público consumidor com hábitos relativamente conhecidos.

d) Com a crise do emprego formal no mundo do trabalho, há um impulso para a formação de pequenas empresas familiares, de ONGs, de cooperativas, de grupos comunitários ou de outras formas de gestão similares.

Além disso, no caso brasileiro, o mercado interno potencial estende-se a mais de 180 milhões de habitantes, que apresentam faixas de renda e necessidades bastante diversificadas, o que abre inúmeras possibilidades dentro do mercado interno (local e em alguns casos, nacional) para a produção dos pequenos empreendimentos. Tratase, portanto, de um dado nada desprezível. A maior parte das transações econômicas não se realizam nos mercados globais e sim nos nacionais. Mais de $80 \%$ da produção 
mundial se destina aos mercados internos dos países. As exportações representam menos de 20\% da produção mundial. Cerca de 9 em cada 10 dos trabalhadores do mundo produzem para os mercados de seus respectivos países. ${ }^{35}$

$\mathrm{Na}$ Amazônia, pessoas, grupos e instituições têm desenvolvido formas de produção e organização social com vistas a vencer barreiras estruturais de emprego e se inserirem no mercado através desses pequenos empreendimentos inovadores. Geralmente, são ações e experiências executadas coletivamente e baseadas principalmente no aproveitamento de recursos naturais, na conservação ambiental, nos saberes tradicionais dos inúmeros grupos sociais da região e nas culturas locais. ${ }^{36}$ Elas propõem formas de organização da produção, fundadas em movimentos e princípios sociais, associativos e em laços de solidariedade do grupo. Este campo apresenta várias linhas. Todos eles buscam garantir a sobrevivência e a melhoria da qualidade de vida material dos envolvidos, mas no exercício do trabalho cotidiano eles propiciam a construção da identidade do grupo e conquistam vitórias no campo da cidadania, da inserção e da emancipação sociais.

Salvo alguns apoios institucionais pontuais, essas ações e experiências não têm sido tomadas como reais possibilidades, capazes de inspirar a formulação de uma nova política socioeconômica que as englobe. Além disso, têm sido deixadas de lado pelo Estado, postura que fragiliza ainda mais a continuidade e o futuro de muitas dessas iniciativas. Como elas estão, ainda, esparsamente distribuídas e pulverizadas nos diversos espaços regionais, somente políticas públicas que voltem sobre elas um olhar menos desconfiado, e sobretudo mais aberto e receptivo aos saberes tradicionais e às ações das camadas mais pobres, contribuirão para multiplicar e disseminar tais experiências. Somente através de sua multiplicação e da apreentação de resultados exitosos, será possível definir e generalizar um novo modelo ou sistema de produção, que seja mais humanizado, mais socialmente integrador, mais equitativo na distribuição dos benefícios sociais, mais compatível com a biodiversidade da natureza amazônica, e, de fato, mais moderno, porque mais democrático.

Apresento, a seguir, alguns exemplos de ações e empreendimentos inovadores.

\section{I Pequenos empreendimentos Que Promovem a reversão}

\section{DE AÇÕES DANOSAS DO PASSADO}

Um espaço para a geração de emprego e renda pode ser criado através da recuperação do desgaste ambiental causado pelo emprego de práticas danosas no passado. A exemplo, em Roraima, na Serra do Tepequém, as crateras deixadas por garimpeiros que trabalharam lá há cinquenta anos extraindo diamantes, começam a ser aproveitadas para o desenvolvimento da piscicultura pelas comunidades locais. No mesmo Estado, pequenos empresários criam tartarugas em cativeiro para venda no mercado local, em substituição à secular captura dessa espécie, que estava ameaçada de extinção. 
Estas têm sido experiências exitosas, assim como a criação de pirarucu em lagos naturais no Amazonas.

\subsection{Aproveitamento de bens Naturais POR COMUnidAdes E EMPRESAS}

No Acre, o aproveitamento da borracha natural da seringueira para a fabricação do "couro vegetal ou ecológico", 37 como substitutivo das peles de animais silvestres, tem criado empregos e proporcionado a melhoria da qualidade de vida dos grupos envolvidos. Móveis artesanais de madeira maciça, com design avançado e criativo, são fabricados no Acre e começam a ser vendidos no centro-sul do país, aproveitando a tradição que possuem os incontáveis marceneiros existentes em todos os estados da região. No Amazonas a pele dos grandes peixes vem sendo aproveitada como um excelente e fino couro. A indústria farmacêutica e de produtos de higiene tem desenvolvido vários medicamentos derivados de espécies nativas da florestas.

Em outros estados, várias experiências começam a despontar, sinalizando formas de uma articulação harmoniosa entre a natureza e o mercado. No Pará, a fabricação de bombons os mais variados a partir dos frutos silvestres vem, timidamente, aparecendo no mercado nacional e, embora ainda sob a forma artesanal e carecendo de um tratamento empresarial mais apurado - como embalagem e conservação mais duradoura. Quanto ao sabor, no entanto, nada ficam a dever aos bons chocolates europeus que circulam pelo mundo sob belas e primorosas embalagens que os valorizam.

O mesmo ocorre com os licores de alta qualidade (de castanha-do-pará e outras espécies frutíferas), que não encontraram maior espaço no mercado por falta de apoio institucional. $\mathrm{O}$ incentivo à fruticultura regional nas áreas já desmatadas pode abrir oportunidades para a geração de emprego e renda para pequenos produtores rurais. É possível usar as franjas das matas próximas às áreas não desmatadas, para aproveitar a umidade de que goza a área de mata; desse modo a possibilidade de sucesso em áreas desgastadas seria relativamente maior. ${ }^{38} \mathrm{O}$ açaí já alcançou o mercado nacional. A produção de castanha-do-pará pode ser estimulada com a castanheira precoce, desenvolvida pela Embrapa-PA, ${ }^{39}$ isto sem falar de outras espécie frutíferas de sabores ímpares.

É evidente que não estou colocando aqui a questão de desenvolver a região a partir, exclusivamente, de pequenos empreendimentos artesanais ou semi-industriais, como os supracitados. A ideia é que, como esses, há incontáveis formas de aproveitamento de produtos que podem ser desenvolvidas; esses empreendimentos, cuja identidade é muito própria porque não convencional e até inovadora, têm a capacidade de projetarse além dos mercados regional e nacional e contam com o possibilidade única do selo "Made in Amazônia" e/ ou "Feitos com frutos ou árvores da Floresta Amazônica".

\subsection{APOIO À gestÃo de ReCURSOS Florestais OU À MODERniZAÇÃo do EXTRATIVISMo}

A gestão dos recursos florestais, com o enriquecimento da floresta, pela substituição de espécies de baixo valor comercial por espécies de elevada procura no mercado, 
pode tornar-se uma atividade altamente salutar por possibilitar a geração de emprego, renda e garantir a sustentabilidade da natureza. Poderá, ainda, viabilizar, através da modernização do extrativismo vegetal, uma variada produção de recursos da floresta, seja de espécies alimentares, de espécies medicinais e outras.

A gestão tem sido praticada por seringueiros, castanheiros, ribeirinhos em geral, e mesmo por pequenos agricultores. Coletadores de castanha voltam a produzir em castanhais abandonados, enriquecem a floresta com novas mudas, saindo da fase puramente extrativista de coleta. Pequenas fábricas produzem aromatizantes, fixadores de perfumes, sabonetes, xampus, azeite, etc. Os sistemas agroflorestais experimentados por sindicatos de trabalhadores rurais e outras organizações no Amapá e em Rondônia ${ }^{40}$ constituem-se em experiências voltadas para a revitalização da Floresta, através do enriquecimento desta com espécies oleaginosas (como a andiroba e a copaíba, ambas com altos e reconhecidos poderes cicatrizantes), e outras com as quais produzem repelentes naturais de insetos, etc. Essas iniciativas, contudo, vêm ocorrendo sem a orientação técnico-científico necessária, por isso enfrenta os problemas e dificuldades já mencionados.

Outro nicho a explorar é o turismo ecológico, que apresenta grande potencial.

Em resumo, situações antes raras e pontuais começam a se multiplicar, trazendo boas expectativas. Nesses casos, embora a iniciativa venha partindo do setor privado, algumas iniciativas têm encontrado valiosas parcerias, o que sinaliza um avanço no sentido desejável.

\section{CONSIDERAÇÕES FINAIS}

O que pensar dessas experiências? Elas são modestas na sua maioria, mas geram emprego e renda. São capazes de incluir socialmente as pessoas e elevarem a autoestima dos que nelas se envolvem; agregam pessoas que saem das margens da sociedade e se engajam ativamente na reprodução da vida social. No entanto, são também experiências que, se de um lado apontam caminhos, de outro exibem suas próprias fragilidades. Em geral, elas carecem de domínio tecnológico, de capital e de conhecimento do mercado. Muitas delas, talvez a maioria, não podem dispensar o apoio do Estado e de segmentos mais estruturados da sociedade, como universidades e empresas, sob pena de sucumbirem; a exemplo do que ocorre com empreendimentos convencionais, para os quais os sistemas econômico e político têm voltado seu apoio, sempre.

A observação das variadas experiências relativas aos empreendimentos em pequenos lotes agrícolas, em sistemas agroflorestais, de turismo ecológico, pesca e inúmeras outras em curso na Amazônia brasileira, desenvolvidas por grupos de pessoas, associações, cooperativas, apoiadas por ONGs nacionais e estrangeiras, fundações, universidades, centros de pesquisa, associações ligadas a igrejas, etc., podem conduzir a algumas conclusões, as quais destaco. 
a) As experiências refletem a construção de outro modo de produção não tipicamente capitalista, sem enfrentar ou desafiar o modo de produção hegemônico do capitalismo globalizado, aliás, diferem significativamente deste, instituindo-se como formas diversas de organização da produção.

b) São formas ou sistemas de produção alternativos em vários sentidos: eles promovem a cidadania, a autoestima e a dignidade das pessoas envolvidas; buscam formas solidárias de sobrevivência coletiva, num mundo abalado pela crise do trabalho e com mercados altamente segmentados, competitivos e controlados, que lhes oferece reduzidas oportunidades de inserção.

c) Essas formas de produção não se encontram fora da lógica do mercado. Ocupam espaços que se situam nos inúmeros interstícios da produção em larga escala, característica do mercado industrializado global e, embora se organizando sob uma característica local e uma escala reduzida, se articulam no mercado interno e, não raro, conseguem ultrapassar os limites do mercado local.

d) Um mínimo de organização empresarial, de qualidade técnica, regularidade de produção, formas adequadas de conservação e embalagem, condições higiênicas e outras são indispensáveis, sem as quais os empreendimentos não conseguem manter-se.

e) Muitas são as dificuldades enfrentadas por esses pequenos empreendimentos, de tal forma que, a ação governamental não pode ser residual e acidental mas, ao contrário, próxima do produtor, sistemática e objetiva. Ao lado das ONGs, universidades, fundações e outras instituições, a presença do Estado, através de seus órgãos ligados ao setor produtivo, torna-se um fator importante como garantia do sucesso dos empreendimentos. Contudo, é imprescindível que o Estado esteja receptivo e disposto a participar.

f) Isto implica a formulação de políticas especificamente destinadas a esses empreendimentos, atentas às suas peculiaridades, sem procurar ajustá-los às normas gerais supostamente igualitárias, que, com frequência, colidem com seus interesses e sob as quais eles se encontram em condições de inferioridade.

g) Embora as oportunidades para se iniciar empreendimentos fundados na economia solidária sejam numerosas, eles enfrentam dificuldades e estrangulamentos diversos - típicos em cada caso e em cada área específica. No caso amazônico, o sucesso nem sempre é garantido. É preciso entender que muitos empreendimentos operam em campos novos, poucas vezes experimentados por outros grupos; 
como consequência, a instabilidade, o risco e a margem de erro dos empreendimentos alternativos são superiores se comparados aos negócios já consagrados pelo mercado capitalista moderno.

h) Dado que se trata de pequenos empreendedores descapitalizados, o tempo de maturação do projeto não pode ser longo ou, quando é longo, é preciso manter uma atividade paralela, capaz de garantir o sustento familiar dos membros envolvidos, sob pena de desistência e abandono do projeto, especialmente nos sistemas agroflorestais (o empreendimento podem ser combinados com a agricultura de ciclo curto).

i) Apesar das limitações e dificuldades que enfrentam, essas experiências apontam caminhos novos de produção da sociedade no espaço amazônico. Sob esse aspecto, os grupos organizados da sociedade civil estão à frente do Estado, no que concerne à busca de alternativas geradoras de emprego, de internalização de benefícios, de construção de uma economia mais consentânea com os conhecimentos populares e mais harmonizados com a natureza.

O mais importante é que através de uma economia popular e solidária, impulsionada de dentro para fora e de "baixo para cima" - considerando o pequeno volume de capital que mobiliza -, pode-se contribuir para a melhoria da qualidade de vida de amplos segmentos da população. ${ }^{41}$

Nos últimos anos, inúmeros grupos e segmentos da sociedade da região apontaram possibilidades novas e alternativas criativas, algumas das quais abordadas neste artigo. São tentativas de afirmação de modelos próprios. São experiências que se desenvolvem através de projetos inovadores, que aproveitam os saberes populares e as potencialidades que eles enxergam como acessíveis e viáveis. São atitudes modestas em sua maioria, mas carregam consigo o dom de incluir grupos esquecidos ou excluídos socialmente e engajá-los ativamente na produção da vida social.

A abertura de políticas públicas para novas experiências implica mudanças de princípios e rupturas com equívocos e preconceitos. A ruptura exige a coragem de inventar modos de produção e de convivência social menos excludentes e mais solidários. Tratase, sem dúvida, de um risco, como é arriscado tudo o que é novo. Mas perpetuar o presente e projetá-lo para o futuro significa cumprir um destino de desigualdade e violência crescente que conhecemos e rejeitamos. É preciso considerar que o futuro é construído sobre utopias formuladas no presente e não como uma continuidade do passado. Entre o passado recente e o futuro há um presente que nos chama à razão e nos incita a uma ruptura com o passado e à projeção de um futuro melhor e mais solidário. 


\section{NOTAS}

1 SANTOS, Boaventura de Sousa. (Org.) Produzir para viver - Os caminhos da produção não capitalista. Porto: Afrontamento, 2004.

2 HIRSCHMAN, Albert. Desenvolvimento por Efeitos em Cadeia - Uma abordagem generalizada. In: Estudos CEBRAP, n. 18, out./dez. São Paulo, 1976.

3 Refiro-me especialmente aos seguintes planos federais para a Amazônia: I Plano de Desenvolvimento da Amazônia, 1972/74; II Plano de Desenvolvimento da Amazônia, 1975/79; III Plano de Desenvolvimento da Amazônia, 1980/85; I Plano de Desenvolvimento da Amazônia, Nova República, mas também os planos estaduais que, na região, seguiram as diretrizes dos nacionais. Os planos federais e estaduais posteriores e atuais, com poucas exceções e em poucos momentos, se distanciaram dos objetivos e métodos dos anteriores, incluindo alguns projetos do Programa de Aceleração do Crescimento (PAC).

4 COSTANZA, R. The ecological economics of sustainability: investing in natural capital. In: Goodland et al. (Orgs.) Environmentally Sustenaible Economic Development: Building on Brundtland. Paris: Unesco, 1991.

5 BHABHA, Homi apud FRIEDMANN, Susan Stanford. O falar da fronteira, o hibridismo e a performatividade: teoria da cultura e da identidade nos espaços intersticiais da diferença. Rev. Crítica de Ciências Sociais, n. 61, p. 1-28, p. 17. 2001.

6 A expressão sistema-mundo ficou amplamente conhecida após seu uso por Immanuel. M Wallerstein, Le systèmemonde du XVe siècle à nos jour. Paris: Flammarion, 1980.

7 SANTOS. Boaventura de Sousa. Poderá o direito ser emancipatório?, Revista Crítica de Ciências Sociais, n. 65, p. 3-76, 2003.

8 Para conhecer algumas das formas de integração forçada dos índios no século 20 há uma enorme produção científica. Ver, p.ex., Carlos Alberto Ricardo, org., Povos indígenas do Brasil - 1991-95 (São Paulo, Instituto Socioambiental, 1996) e, do mesmo autor, Povos indígenas do Brasil - 1996-2000 (São Paulo, Instituto Socioambiental, 2001).

9 Elas correspondem a 12,54\% do território brasileiro e a 20\% da Amazônia, já que 405 (69\%) do total das terras indígenas encontram-se na Amazônia Legal. A extensão delas na região corresponde a 98,6\% do total existente no país, enquanto os 1,4\% restantes estão distribuídos por outros pontos em todo o território nacional (Funai/2005).

10 COUTINHO, Leonardo. Menos de 1\% tem o selo verde, Veja, a. 38, n. 45, p. 66-67, 9 nov. 2005.

11 A atual pecuária é conhecida como a moderna pecuária (para diferi-la da dos anos 1970/1980) porque tratase do chamado "boi orgânico", que vive solto no pasto, se alimenta de capim e melhorou em termos de tratamento genético e sanitário.

12 DIAZ, Maria del Carmen Vera. Incorporando a exaustão das reservas minerais ao Produto Interno Bruto do Estado do Pará. Belém: Ufpa: Núcleo de Altos Estudos Amazônicos, Curso Internacional de Mestrado em Planejamento do Desenvolvimento, 1999, inédito.

13 Grupos indígenas de alguma forma afetados pela BR-163:Apiretewa; Arara; Arawetê; Assurini; Aweti; Bakairi; Juruna; Kaiapó;Kalapalo; Kamayurá; Kararaô; Kayabi; Kuruaya; Matipu; Mekragnoti; Mentuktire; Munduruku; Nahukwá; Panará; Parakanã; Paresi; Saterê-Mawe; Suyá; Tapayúna; Trumai; Txicão; Waurá; Xavante; Xikrin; Xipaia; Yawalapiti. Fontes: CIMI, MMA, Ibama e Ipaam.

14 EIA/RIMA. Disponível em : <www.eletrobrás.com>.

15 GUIMARÃES, Ed C. Trabalho cativo por dívida na Amazônia paraense. 2005. Disssertação de (Mestrado) Centro de Estudos Jurídicos. Belém: Universidade Federal do Pará.

16 A concepção desse sistema como arcaico tem sido levantado por mim desde o início dos anos 1990 em vários trabalhos publicados. Inúmeros outros autores levantaram relevantes problemas concernentes ao modelo. Lamentavelmente, 
os setores governamentais e empresariais permanecem com o discurso da modernização (fazendo ou não ressalvas do ponto de vista ambiental, mas sem agirem efetivamente sobre ele). E mais - sem vincular a ele a questão social e sem apontar seu caráter arcaico.

17 BAUMAN, Sygmunt. Globalização: as consequências humanas. Rio de Janeiro: Zahar, 1999, cap. 4 e 5.

18 Em 2000, segundo o Atlas de Desenvolvimento Humano no Brasil, PNUD, ONU, eram os seguintes os percentuais de pessoas com renda per capita abaixo de 30 dólares em alguns estados: Acre (47,83\%), Amapá (42,95\%), Amazonas (52,97\%), Pará (51,89\%), Rondônia (35,20\%), Roraima (35,90\%), Tocantins (50,79\%). Disponível em: $<$ www.pnud.org.br>.

19 LOUREIRO, Violeta R.. Prejugés et modèle: les plans d'intégration économique de l 'Amazonie brésiliènne où la modernisation a rebours. Paris: Maison des Sciences de l’Homme, Cahiers du Brésil Contemporain, Paris, n. 21, p. 63-83, 1993; LOUREIRO, V. R. Pressupostos do modelo de integração da Amazônia brasileira aos mercados nacional e internacional em vigência nas últimas décadas: a modernização às avessas. Sociologia na Amazônia - debates teóricos e experiências de pesquisa. Belém: EDUFPA, 2001, p. 31-47.

20 VIEIRA, Ima Célia G. et al. Diversidade biológica e cultural da Amazônia. Belém: MPEG, 2001.

21 ANDRADE, Lúcia; VIVEIROS DE CASTRO, Eduardo. Hidrelétricas do Xingu: o Estado contra as Sociedades Indígenas. In: Leinarde Santos; e Lúcia Andrade. As hidrelétricas do Xingu e os povos indígenas. São Paulo: Comissão Pró-Indio de São Paulo, 1988.

22 SANTOS, Boaventura de Sousa Santos. (Org.) Produzir para Viver - Os caminhos da produção não capitalista. Porto: Afrontamento, 2004, p. 21-66.

23 BUEY, Francisco Fernandez. Guía para una Globalización Alternativa - otro mundo es posible. Barcelona: Ediciones "B", 2005.

24 LOUREIRO, Violeta R. Amazônia no século XXI: novas formas de desenvolvimento. São Paulo: Empório do Livro, 2009.

25 A ideia vem sendo posta em ação no Estado do Amazonas pelo governo local. Embora os valores da referida bolsa sejam muito baixos, é uma boa iniciativa no esforço de manter a floresta em pé; além do que, os extrativistas recebem assistência técnica e outros apoios.

26 Não cabe aqui discutir a medida precipitada do Governo Federal de fazer concessões de florestas nacionais para manejo sustentado por trinta, quarenta anos, quando o próprio governo não tem condições mínimas de fiscalizar sequer os desmatamentos ilegais, quanto mais estendendo os espaços com novas áreas abertas à exploração florestal.

27 Conforme AB'SABER, Aziz Nacib. As etnociências e o legado de Darrell Posey. Scientific American Brasil, agosto, 2002. Disponível em: <http://www.sciam.com.br>.

28 RIECHMANN, Jorge. (Coord.) Necesitar, desear, vivir: sobre necesidades, desarrollo humano, crecimiento económico y sustentabilidad. Madrid: Los Libros de la Catarata, 1998.

29 BRASIL. MINISTÉRIO DO MEIO AMBIENTE. A grilagem de terras públicas na Amazônia. Brasília: MMA, Série Estudos, n. 8, 2006.

30 Folha de São Paulo, 9 de maio de 2009.

31 Dados de 2009 contidos no Relatório Preliminar da Comissão acima referida (CJCI-TJE-PA).

32 A Companhia Vale do Rio Doce, quando ainda era uma estatal investia no Pará e em Minas Gerais $8 \%$ do seu lucro líquido em obras de caráter social e de infraestruturas e, ainda assim, era uma das mais rentáveis empresas siderúrgicas do mundo. Ao ser privatizada por apenas 3 bilhões de dólares, a obrigatoriedade da aplicação deixou imediatamente de ser feita. 
33 Apenas 0,7\% do Produto Interno Bruto (PIB) é investido em pesquisa no Brasil, e deste montante 57,46\% são canalisados para a região Sudeste; $13 \%$ para o Sul; 10,4\% para o Nordeste; $7 \%$ para o Centro-Oeste; $2 \%$ para o Norte. $\mathrm{CNPq} / \mathrm{MCT} / 2005$.

34 BECKER, Bertha; LÉNA, Philippe. (Orgs.) Pequenos empreendimentos alternativos na Amazônia. In: Rede de sistemas produtivos e inovativos locais. Rio de Janeiro: Sebrae; Finep; CNPq, UFRJ, 2002 (aponta instituições internacionais e nacionais de apoio a projetos inovadores na Amazônia, assim como as associações responsáveis por vários dos pequenos projetos por eles analisados).

35 FERRER, Aldo. Hechos y Ficciones de la Globalización. Buenos Aires. Fondo de Cultura Económica, 1997, p. 30.

36 DIEGUES, Antônio Carlos ; ARRUDA, Rinaldo S. V. (Orgs.) Saberes tradicionais e biodiversidade no Brasil. Brasília: MMA; São Paulo: USP, 2001

37 Trata-se do aperfeiçoamento do saco de tecido (embalagens de trigo) emborrachado que os coletadores de seringa usavam no passado. O látex é quimicamente tratado e defumado. A partir daí são produzidas peças "em couro", com $2 \mathrm{~m}$ por 1,4 m, à semelhança do couro de boi ou outro. Serve para a confecção de roupas, forro para capacetes, bolsas, etc.

38 AB'SABER, Aziz Nacib. Economia ecologicamente sustentável. Scientific American Brazil, nov. 2004.

39 Uma castanheira nativa atinge em média $20 \mathrm{~m}$ de altura e dura 300 anos, mas exige um tempo de maturação entre 15 a 20 anos. A castanheira precoce desenvolvida pela Embrapa-PA dá frutos em 8 a 9 anos.

40 RECA - Reflorestamento Econômico Consorciado Adensado (ver Becker e Léna, op. cit., p. 18-20).

41 Ver sobre economia solidária, p.ex., ARROYO, João Cláudio Tupinambá; SCHUCH, Flávio Camargo. Economia Popular e solidária: alavanca para um desenvolvimento sustentável. São Paulo: Fundação Perseu Abramo, 2006, p. 63-65.

\section{REFERÊNCIAS BIBLIOGRÁFICAS}

AB’SÁBER, Aziz Nacib. As etnociências e o legado de Darrell Posey. Scientific American Brasil, ago. 2002. Ver também www.sciam.com.br.

ANDRADE, Lúcia; VIVEIROS DE CASTRO, Eduardo. Hidrelétricas do Xingu: o Estado contra as Sociedades Indígenas. In: Leinarde Santos; Lúcia Andrade. As hidrelétricas do Xingu e os povos indígenas. São Paulo: Comissão Pró-Indio de São Paulo, 1988.

BAUMAN, Sygmunt. Globalização: as consequências humanas. Rio de Janeiro: Zahar, 1999.

BRASIL. MINISTÉRIO DO MEIO AMBIENTE. A grilagem de terras públicas na Amazônia. Brasília: MMA, Série Estudos, n. 8, 2006.

BUEY, Francisco Fernandez. Guía para una Globalización Alternativa - otro mundo es posible. Barcelona: Ediciones "B", 2005.

COSTANZA, R. The ecological economics of sustainability: investing in natural capital. In: GOODLAND et al. (Orgs.) Environmentally Sustenaible Economic Development: Building on Brundtland. Paris: Unesco, 1991.

COUTINHO, Leonardo. Menos de 1\% tem o selo verde. Veja, a. 38, n. 45, p. 66-67, 9 nov. 2005

DIAZ, Maria del Carmen Vera. Incorporando a exaustão das reservas minerais ao Produto Interno Bruto do Estado do Pará. Belém: Universidade Federal do Pará; Núcleo de Altos Estudos Amazônicos, Curso Internacional de Mestrado em Planejamento do Desenvolvimento, 1999, inédito.

DIEGUES, Antônio Carlos ; ARRUDA, Rinaldo S.V. (Orgs.) saberes tradicionais e biodiversidade no Brasil. Brasília: MMA; São Paulo: USP, 2001.

GUIMARÃES, Ed Carlos. Trabalho cativo por dívida na Amazônia Paraense. Belém: Universidade Federal do Pará, Centro de Estudos Jurídicos. Disssertação de Mestrado apresentada no Programa de Pós-graduação em Direitos Humanos, inédita, 2005.

HIRSCHMAN, Albert. Desenvolvimento por efeitos em cadeia - Uma abordagem generalizada. Estudos Cebrap, n. 18, out./dez, SP, 1976. 
LOUREIRO, Violeta R.. Préjugés et modèle: les plans d'intégration économique de 1'Amazonie brésilienne où la modernisation a rebours. Cahiers du Brésil Contemporain, n. 21. Paris: Maison des Sciences de l'Homme, 1993.

. Pressupostos do modelo de integração da Amazônia brasileira aos mercados nacional e internacional em

vigência nas últimas décadas: a modernização às avessas. In: Maria José Jackson Costa ; Wilson José Barp. (Orgs.)

Sociologia na Amazônia: debates teóricos e experiências de pesquisa. Belém: Ed. da UFPA, 2001

. Amazônia no século XXI: novas formas de desenvolvimento. São Paulo: Empório do Livro, 2009.

ONU/PNUD. Atlas de Desenvolvimento Humano no Brasil/2000. Disponível em:

http: / / www.pnud.org.br/IDH/Atlas2003.aspx?indiceAccordion=1\&li=li_Atlas2003.

RICARDO, Carlos Alberto. (Org.) Povos indígenas do Brasil - 1991-1995. São Paulo: Instituto Socioambental, 1996. . Povos Indígenas do Brasil - 1996-2000. São Paulo: Instituto Socioambental, 2001.

RIECHMANN, Jorge. (Coord.) Necesitar, desear, vivir: sobre necesidades, desarrollo humano, crecimiento económico y sustentabilidad. Madrid: Los Libros de la Catarata, 1998.

SANTOS, Boaventura de Souza. Poderá o direito ser emancipatório? Revista Crítica de Ciências Sociais, Coimbra, n. 65, p. 3-76, 2003.

SANTOS, Boaventura de Sousa. (Org.). Produzir para Viver - os caminhos da produção não capitalista. Porto:

Afrontamento, 2004.

SOUZA FILHO, Carlos Frederico Marés. Multiculturalismo e direitos coletivos. In: Boaventura de Souza Santos (Org.) Reconhecer para libertar. Porto: Afrontamento, 2004.

VIEIRA, Ima Célia G. et al. Diversidade biológica e cultural da Amazônia. Belém: MPEG, 2001.

WALLERSTEIN, Immanuel. M. Le système-monde du XV siècle à nos jours. Paris: Flammarion, 1980.

Violeta Refkalefsky Loureiro

Universidade Federal do Pará Instituto de Ciências Jurídicas - PPGD

Rua Augusto Correa, n. 1 Guamá - 66075-900 Belém - PA - Brasil

violeta.loureirolaig.com. br
Doutora em Sociologia PELA Universidade de Paris III

Professora do Programa de Pós-graduação em Clências Socials e do Programa de Pós-graduação EM DIREITO NA UFPA 